\title{
Identification and Enumeration Method of Both Eukaryotic and Prokaryotic Microorganisms in Food Sample
}

\author{
Katsuji Watanabe $^{1 *}$, Naoto Horinishi ${ }^{1}$, Kunimasa Matsumoto ${ }^{1}$, Yuji Sogabe ${ }^{2}$ \\ ${ }^{1}$ Department of Life, Environment and Materials Science, Graduate School of Engineering, Fukuoka Institute of \\ Technology, Fukuoka, Japan \\ ${ }^{2}$ Global Application Development Center, Shimadzu Co., Kyoto, Japan \\ Email: ${ }^{*}$ k-watanabe@fit.ac.jp
}

Received 23 January 2016; accepted 25 April 2016; published 28 April 2016

Copyright (C) 2016 by authors and Scientific Research Publishing Inc.

This work is licensed under the Creative Commons Attribution International License (CC BY). http://creativecommons.org/licenses/by/4.0/

(c) (i) Open Access

\begin{abstract}
The method to analyze both eukaryotic and prokaryotic microorganisms without preliminary microbial information of sample seemed to be useful not only for research and investigation of microorganisms but also for industry using microorganisms. In the present manuscript, preparation of a new DNA primers, new reference database for $18 \mathrm{~S}$ rDNA for our newly developed method [1][3], and analyses of eukaryotic and prokaryotic microorganisms in fermentation products were presented. In komekouji, Aspergillus spp., was enumerated to be $46.5 \times 10^{6} \mathrm{MPN} \mathrm{g}^{-1}$, and Penicillium spp., was enumerated to be $1.5 \times 10^{6} \mathrm{MPN}^{-1}$. In dry yeast, Saccharomyces group, were enumerated to be $8600 \times 10^{6} \mathrm{MPN}^{-1}$. In komekouji-miso, no eukaryotic microorganism was detected, while the other Bacillus spp., was numerically dominant $\left(21.5 \times 10^{6} \mathrm{MPN}^{-1}\right)$ as prokaryotic microorganisms, followed by $B$. subtilis group $\left(4.65 \times 10^{6} \mathrm{MPN} \mathrm{g}^{-1}\right)$, and the other Firmicutes $(3.7 \times$ $\left.10^{6} \mathrm{MPN} \mathrm{g}^{-1}\right)$. The komekouji-miso included lower number of Actinobacteria $\left(0.15 \times 10^{6} \mathrm{MPN} \mathrm{g}^{-1}\right)$, Burkhokderia sp. $\left(1.5 \times 10^{6} \mathrm{MPN} \mathrm{g}^{-1}\right)$, and the other $\alpha, \beta, \gamma$-proteobacteria $\left(0.12 \times 10^{6} \mathrm{MPN}^{-1}\right)$. In sake-kasu, both prokaryote and eukaryote were not detected by the method. Present results indicated that using both universal primers for eukaryotic and prokaryotic microorganisms, each groups of prokaryotic and eukaryotic microorganisms were enumerated without any preliminary information nor setting up standard curve, which were required for real time PCR.
\end{abstract}

\section{Keywords}

Eukaryotic Microorganisms, Prokaryotic Microorganisms, Multiple Enzyme Restriction Fragment Length Polymorphism Analysis, the Most Probable Number Method, Microchip Electrophoresis

\footnotetext{
${ }^{*}$ Corresponding author.
}

How to cite this paper: Watanabe, K., Horinishi, N., Matsumoto, K. and Sogabe, Y. (2016) Identification and Enumeration Method of Both Eukaryotic and Prokaryotic Microorganisms in Food Sample. Food and Nutrition Sciences, 7, 345-354. 


\section{Introduction}

By PCR-based analysis methods such as real time quantitative PCR (qPCR) or multiplex PCR, eukaryotic and prokaryotic microorganisms [4]-[7] could be detected or quantified by the same procedure by changing used DNA primers. By qPCR using universal primer for the both microorganisms, total numbers of eukaryote and prokaryote in sample could be enumerated, however we could not know what kinds of microorganisms were mainly included without analyzing amplified DNA [4]. By the multiplex PCR or qPCR using several selective primers, the exact numbers of each specific microorganisms could be detected or enumerated, however we could not know what kinds of microorganisms were mainly included, because selective primer targeted the specific microorganisms and afford no-information as to microorganisms which were not covered by the used primers [4] [8]-[10]. Although denaturing gradient gel electrophoresis (DGGE) [11]-[14] provided taxonomical information of each microbial group and had been used for exploration of microbial diversity. We could not know relative abundance of each microbial group exactly, because of the PCR bias, which altered the ratio of each microbial groups in the amplified DNA from that of original DNA in sample [15]-[18]. Moreover we could not compare a number of eukaryote to that of prokaryote obtained by different PCR primers, respectively [11]-[14], because the amplification rate and PCR bias were varied with the used DNA primers.

The method to compare the both eukaryote and prokaryote directly without preliminary microbial information of sample seemed to be useful not only for research and investigation of microorganisms but also for industry using microorganisms.

Until now, we had developed a new affiliation system based on multiple enzyme restriction fragment polymorphism analysis (MERFLP), by which bacteria was systematically affiliated [1], and the method to provide numbers of each taxonomically different bacterial groups in the former papers [2] [3]. Although the same primers for 16S rDNA (41f/1066r) had been used until now, the other DNA primer could additionally be used for the analysis. In the present manuscript, preparation of a new DNA primers, PCR condition, and new reference DNA database for 18S rDNA, and microbial analysis of fermentation products by the both primers for the $16 \mathrm{~S}$ rDNA and the $18 \mathrm{~S}$ rDNA were presented.

\section{Materials and Methods}

\subsection{Samples and Isolation of Microorganisms}

Precision of the affiliation and enumeration of microorganisms in sample was found to be depend on a microbial diversity in the sample. Kome-kouji (K), which included kouji proliferated on steamed rice and used as seed for fermentation, was selected as a representative sample including higher ratio of Aspergillus oryzae. Dry yeast (P) was selected as a representative sample including higher ratio of Saccaromyces sp. Komekouji-miso (M), which was a traditional fermentation product of soybean by addition of kome-kouji, was selected as a representative sample including lower ratio of eukaryotic microorganisms and higher ratio of prokaryotic microorganisms. Sake-kasu (S), which was a residual material after filtering rice wine from moromi where rice was fermented using kouji and yeast, was selected as a representative sample including lower ratio of both eukaryotic and prokaryotic microorganisms.

For MPN, serial 10-fold dilutions $\left(10^{-3}\right.$ to $\left.10^{-9}\right)$ prepared from sample (1 g fresh wt.) were inoculated to test vials (3 replicates) including potato dextrose medium (potato extract $4 \mathrm{~g}$, dextrose $20 \mathrm{~g} \cdot \mathrm{L}^{-1}$ ). Microbial DNAs were extracted after 3 days of the incubation. Reference strains of Penicillium roqueforti (NBRC5459), Giberellazeae (NBRC7189), Aspergillus oryzae (NBRC30113) and Saccharomyces uvarum $\left(\mathrm{NBRC}^{10968^{\mathrm{T}}}\right.$ ) were purchased from NBRC (NITE Chiba Japan).

Microorganisms were newly isolated from komekouji (K; 3 isolates), sake-kasu (K; 5 isolates), dry yeast (P; 3 isolates), and komekouji-miso (M; 5 isolates) using an agar plate containing potato dextrose medium. As eukaryotic microorganisms were not isolated from sake-kasu (K) and komekouji-miso (M), prokaryotic microorganisms were isolated from the both samples.

\subsection{PCR Amplification of $18 \mathrm{~S}$ rDNA and $16 \mathrm{~S}$ rDNA and Their Restriction Digestion}

Chromosomal DNAs of each MPN vials and isolates were extracted by bead beating (3000 rpm 2 min; shakeMan 2, Biomedical Science Co., Tokyo, Japan) using zirconia beads (diameter $2.3 \mathrm{~mm}$ ) according to the manufacture's instruction, and purified by conventional methods, which was used for the both 16S rDNA and 18S 
rDNA analyses.

DNA primers for 18S rDNA (forward primer EF41; 5'GGAAKGGRTGYAYTTAYYAG3', reverse primer EF31; 3'GYTTDSACCRRTAAATCTCCT5') were newly designed based on those of the reported DNA primers (EF4/EF3), and PCR condition was also little modified from those of the reported PCR condition [19] [20] because some of isolated fungi were not amplified by the EF4/EF3. After denaturation at $94^{\circ} \mathrm{C}$ for $1 \mathrm{~min}, 18 \mathrm{~S}$ rDNA was amplified with the following parameters; 40 cycles of denaturation at $94^{\circ} \mathrm{C}$ for $1 \mathrm{~min}$, primer annealing at $51^{\circ} \mathrm{C}$ for $1 \mathrm{~min}$, and primer extension of $72^{\circ} \mathrm{C}$ for $3 \mathrm{~min}$. After amplification cycles, the final elongation step lasted for $10 \mathrm{~min}$ at $72^{\circ} \mathrm{C}$.

Amplification of 16S rDNA was according to the former study [21] [22] using the 41f forward primer (V2), and the 1066r reverse primer (V6) [23]. After restriction digestion of the PCR product (10 $\mu$ l) by each restriction enzyme, HaeIII or HhaI or Rsa I or AluI (10 units, Takara Bio Co. Ltd. Shiga Japan) in buffer solution (10xLow salt buffer, Takara Bio Co. Ltd.) and 5 folds dilution by de-ionized water, restriction fragment lengths were measured by microchip electrophoresis system (MCE-202 MultiNA; Shimadzu Co., Ltd. Kyoto Japan).

\subsection{Reference MERFL Database for EF41/EF31 and 41f/1066r Used for the Phylogenetic Estimation}

The database for 18S rDNA was newly edited using the method of Watanabe and Okuda [1] as described previously [21]. For EF41/EF31 primers, 2154 post-amplification sequence files, which were consisted from 897 eukaryotic genera, including uncultured and unidentified microorganisms, were mainly re-edited using small subunit rRNA files in RDP II release 9_61 [24] under 5 - bases mismatches in the both in primer annealing sites. By checking the database it was re-confirmed that the primers selectively amplified fungi and yeast with no cross reactivity to bacteria, algae, plants and nematodes as reported for the original EF4/EF3 primer [19]. Compared to the database for 41f/1066r primers, which had also been edited from small subunit rRNA files in RDP II release 9_61 [24], total number of MERFLs for EF41/EF31 primers (2154 MERFLs) were much lower (30,844 MERFLs), which was caused from lower number of 18S rDNA registered in RDP II release 9_61 [24], and lower ratio of the registered 18S rDNA with whole length of this gene in spite that MERFL database for EF41/EF31 primers required almost whole length of the 18S rDNA (1555 bp DNA for S. cerevisiae (SayCe101), 1558 bp DNA for A. oryza (Aspe. Oryza), and 1557 bp DNA for P. roqueforti (GQ458035).

For the phylogenetic analysis fragment smaller than 100 bp were eliminated from the both theoretical MERFL database and measured MERFL as described previously [21] [22].

\subsection{Selection of MERFL Originated from Homogeneous rDNA Sequence from Mixed MERFLs and Phylogenetic Estimation}

As the reference MERFL databases were for the homogeneous 16S rDNA and 18S rDNA, the measured MERFL originated from the homogeneous 16S rDNA and 18S rDNA had to be selected among the mixed MERFLs for phylogenetic estimation. The major RFs (H) having the highest relative mole concentration (ratio of fluorescent intensity to fragment size) were selected among the mixed RFs as described previously [2]. The 2nd major RFs (M) were selected among the remained FRs after subtraction of the major RFs. The 3rd major RFs (L) were selected among the remained FRs after subtraction of the 2nd major RFs.

For similarity search, the theoretical MERFL (B) having the lowest pairwise distance $\left(D_{A B M E}\right)$ to the measured MERFL (A), which was an average of all the pairwise distance for used restriction enzymes $\left(D_{A B s}\right)$ calculated according to Nei and Li [25], were searched in the reference database as described previously [21]. The equation $\left.\left(1-D_{A B M E}\right) \times 100\right)$ was used as similarity $(\%)$.

In similarity search, identical reference MERFL (100\%) was searched by using all the MERFL preferentially. In case when the $100 \%$ identical reference MERFL was not found, combinations of fewer RFs was used for the next searches (Table 1). In case when the 100\% identical reference MERFL (100\%) was not found using 2 RFs, the reference MERFL with the highest similarity was indicated in Table 1 [2] [3].

\subsection{Estimation of Each Microbiological Numbers by MPN}

Most probable numbers of each groups (A - M) were estimated by 3 tube, 3 decimal dilution experiment [26] (Table 2). Confidence limits were obtained using FDA’s Bacterial Analytical Manual [26] (Table 2). 
Table 1. Affiliation of microorganisms by MERFLP ${ }^{\mathrm{a}}$ of $16 \mathrm{~S}$ rDNA(A-H) and 18S rDNA(I-M).

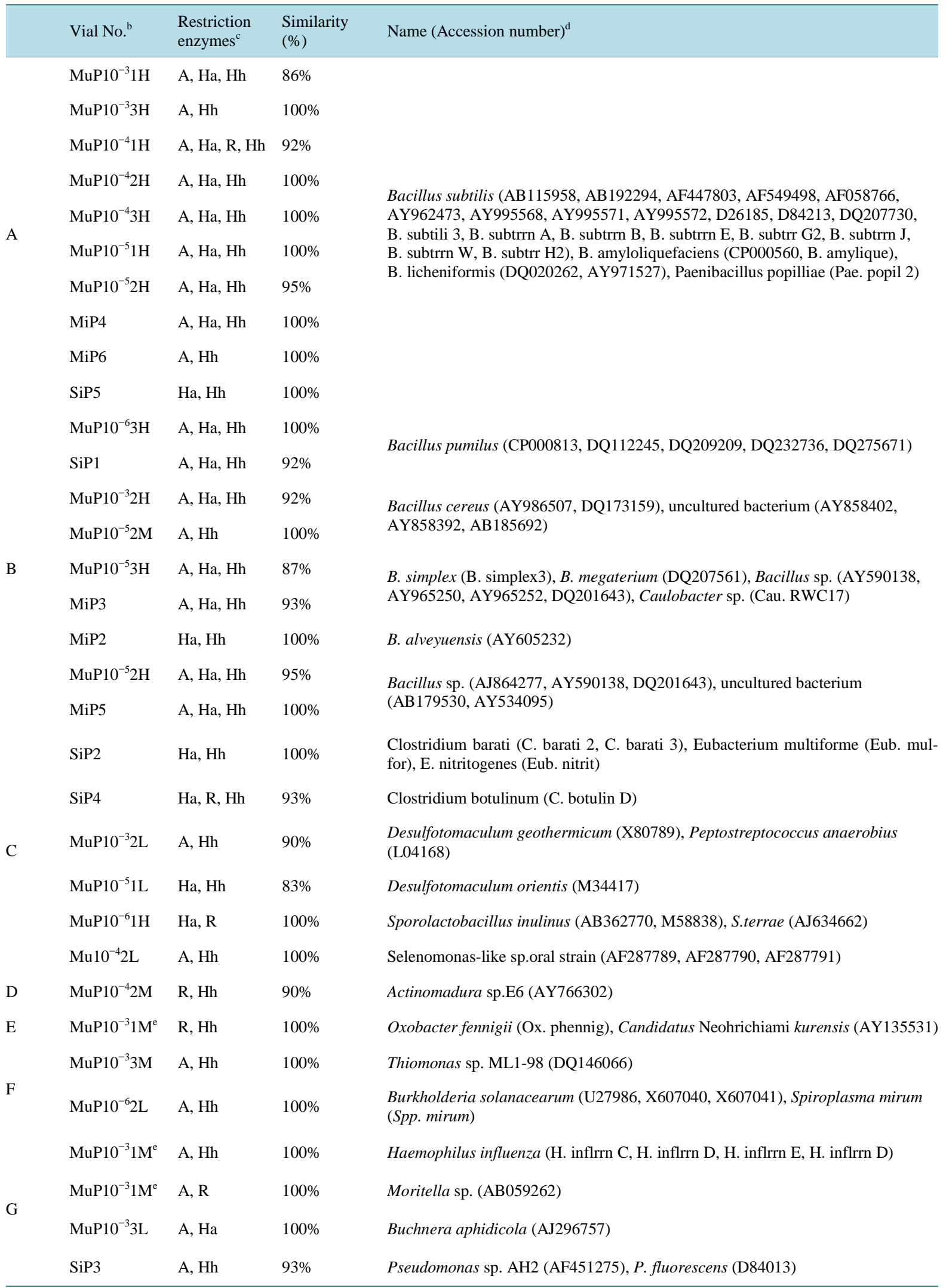




\section{Continued}

\begin{tabular}{|c|c|c|c|c|}
\hline \multirow{5}{*}{$\mathrm{H}$} & $\mathrm{MuP} 10^{-3} 2 \mathrm{M}$ & A, Hh & $93 \%$ & \multirow{5}{*}{$\begin{array}{l}\text { unidentified and uncultured bacterium (AB179495, AF317770, AF371874, } \\
\text { AY177783, DQ129379) }\end{array}$} \\
\hline & $\mathrm{MuP} 10^{-4} 1 \mathrm{M}$ & $\mathrm{Ha}, \mathrm{Hh}$ & $93 \%$ & \\
\hline & $\mathrm{MuP}^{-4} 0^{-4} 3 \mathrm{M}$ & $\mathrm{A}, \mathrm{Hh}$ & $93 \%$ & \\
\hline & $\mathrm{MuP} 10^{-5} 2 \mathrm{~L}$ & $\mathrm{R}, \mathrm{Hh}$ & $90 \%$ & \\
\hline & $\mathrm{MuP} 10^{-6} 2 \mathrm{M}$ & $\mathrm{Ha}, \mathrm{Hh}$ & $93 \%$ & \\
\hline \multirow{8}{*}{ I } & RefESU & $\mathrm{R}, \mathrm{Hh}, \mathrm{A}$ & $100 \%$ & \multirow{8}{*}{$\begin{array}{l}\text { Saccharomyces cerevisiae (SayCe 101), S. dairenensis (SayDair8), } \\
\text { Zygosaccharomyces microellipsoides (Zygs. micro), Z. mrakii (Zygs. mraki), } \\
\text { Z. mellis (Zygs. melli), Torulospora delbrueckii (TorDe113), T. globosa } \\
\text { (Trls. globo), T. pretoriensis (Trls. preto), Kluyveromyces delphensis (KluDeip4), } \\
\text { K. polysporus (KluPoly8), Kazachstania vitcola (X99526), Candida colliculosa } \\
\text { (Can. colli) }\end{array}$} \\
\hline & PiE1 & Ha, R, Hh, A & $100 \%$ & \\
\hline & PiE2 & Ha, R, Hh, A & $100 \%$ & \\
\hline & PiE3 & Ha, R, Hh, A & $100 \%$ & \\
\hline & $\mathrm{PuE} 10^{-8} 1 \mathrm{H}$ & Ha, R, Hh, A & $100 \%$ & \\
\hline & $\mathrm{PuE} 10^{-8} 2 \mathrm{H}$ & Ha, R, Hh, A & $100 \%$ & \\
\hline & $\mathrm{PuE} 10^{-8} 3 \mathrm{H}$ & Ha, R, Hh & $100 \%$ & \\
\hline & $\mathrm{PuE} 10^{-9} 2 \mathrm{H}$ & Ha, R, Hh, A & $100 \%$ & \\
\hline \multirow[t]{2}{*}{$\mathrm{J}$} & RefEGZ & Ha, R & $92 \%$ & \multirow[t]{2}{*}{ Gibberella zeae (AB250414), G. intermedia (JN236216) } \\
\hline & RefEPC & Ha, R, Hh, A & $100 \%$ & \\
\hline \multirow[t]{2}{*}{$\mathrm{K}$} & KiE2 & Ha, Hh, A & $93 \%$ & \multirow[t]{2}{*}{$\begin{array}{l}\text { P. chrysogenum (AFF411201, AF548086), P. expansum (DQ912698), } \\
\text { P. camemberti (GQ458020) }\end{array}$} \\
\hline & $\mathrm{KuE} 10^{-6} 1 \mathrm{H}$ & , Hh, R, A & $97 \%$ & \\
\hline \multirow{8}{*}{$\mathrm{L}$} & RefEAO & Ha, R, Hh, A & $100 \%$ & \multirow{8}{*}{$\begin{array}{l}\text { Aspergillus clavatus (Asp. Clav9), A.awamori (Aspe. awamo), A. fumigatus } \\
\text { (Aspe. fumig, Asp. fumi 2, Asp. fumi 9), A. niger (Aspe. niger), A. parasiticus } \\
\text { (Aspe. psiti), A. restrictus (AspRes10), A. terreus (Asp. Ter15), A.sparsusr } \\
\text { (AspSpar2), P. tardum (AF245256), P. purpurogenum (AF245261, AF245264), } \\
\text { P. glabrum (AF245270), P. decumbens (EU136028), Eremascus albus } \\
\text { (Erms. albus), Elaphomyces maculatus (EloMacul), Eurotium herbariorum } \\
\text { (EutHerba) }\end{array}$} \\
\hline & KiE3 & Ha, Hh, A & $100 \%$ & \\
\hline & KiE4 & Ha, Hh, A & $100 \%$ & \\
\hline & $\mathrm{KuE} 10^{-5} 1 \mathrm{H}$ & Ha, Hh, A & $100 \%$ & \\
\hline & $\mathrm{KuE} 10^{-5} 2 \mathrm{H}$ & Ha, Hh, R, A & $95 \%$ & \\
\hline & $\mathrm{KuE} 10^{-5} 3 \mathrm{H}$ & $\mathrm{HaHh}, \mathrm{A}$ & $100 \%$ & \\
\hline & $\mathrm{KuE} 10^{-6} 2 \mathrm{H}$ & Ha, Hh, A & $97 \%$ & \\
\hline & $\mathrm{KuE} 10^{-6} 3 \mathrm{H}$ & Ha, Hh, A & $97 \%$ & \\
\hline
\end{tabular}

${ }^{\mathrm{a} G r o u p i n g ~ w a s ~ b a s e d ~ o n ~ a f f i l i a t i o n ~ b y ~ M E R F L ; ~ B a c i l l u s ~ s u b t i l i s ~ g r o u p ~(G r o u p ~ A), ~ t h e ~ o t h e r ~ B a c i l l u s ~ s p p . ~(G r o u p ~ B), ~ t h e ~ o t h e r ~ F i r m i c u t e s ~(G r o u p ~ C), ~}$ $\alpha$-Proteobacteria (Group D), $\beta$-Proteobacteria (Group E), $\gamma$-Proteobacteria (Group F), $\delta$-Proteobacteria (Group G), unidentified and uncultured bacterial group (Group H), Hemiascomycetes (Group I), Sordariomycetes (Group J), Eurotiomycetes (Penicillium spp.; Group K), and Eurotiomycetes (Aspergillus spp.; Group L). 'The 1st letter in vial indicates origins of microorganisms; "Ref" stands for reference strains (SU; Saccharomyces uvarum (NBRC10968 ${ }^{\mathrm{T}}$ ), GZ; Gibberella zeae (NBRC7189), PC; Penicillium roqueforti (NBRC5459), AO; Aspergillus oryzae (NBRC30113)), "M" stands for the sample from komekouji-miso, "S" stands for the sample from sake-kasu, "P" stands for the sample from dry yeast, and "K" stands for the sample from komekouji The next letter in the samples means origins of DNAs; "i" means DNA from microbial isolate, and "u" means DNA from culture medium. The next letter indicates used DNA primers; "P" stand for 41f/1066r primers for 16S DNA, and "E" stand for EF4/EF3 primers for $18 S$ rDNA. Vial number in the isolate represents strain number. Exponential of vial number in un isolated DNA (u) represents the decimal dilution of the vial. The 2nd number of vial number (1-3) represents number in 3 replicates for the each decimal dilution. $\mathrm{H}$ of last letter represents MERFL originating from the major 16S rDNA, M represents from the 2nd major 16S rDNA, and L represents from the 3rd major 16S rDNA. 'Restriction enzymes used for similarity search; "Ha", "R", "Hh", and "A" stand for Hae III, RsaI, Hha I, andAluI. For the measured MERFLP which had no completely identical theoretical MERFLP, the theoretical MERFLP having the highest similarity using all the RFLPs was presented with the similarity as described in the materials and method. ${ }^{\mathrm{d} S p e c i e s}$ name (accession number) of the theoretical MERFL having the highest similarity with the measured MERFL. ${ }^{\mathrm{e}}$ Additional name (accession number) of the theoretical MERFL using the different restriction enzymes.

\section{Results and Discussions}

\subsection{Affiliation of Isolated and Non-Isolated Microorganisms by MERFLP}

Affiliations of 27 MERFLs for 18S rDNA of reference strains (4 strains), isolates (13 strains), and each MPN vials (10 genomes), and those of 36 MERFLs for 16S rDNA of isolates (10 isolates), and each MPN vials (26 genomes) were summarized in Table 1. MERFLs for 16S rDNA were divided into 8 groups for the MPN calculation as the followings; B.subtilis group (Group A, 10 MERFLPs), Bacillus spp. (Group B, 9 MERFLs), the other Firmicutes (Group C, 6 MERFLs), Actinobacteria (Group D, 1 MERFL), $\alpha$-Proteobacteria (Group E, 1 
Table 2. Most probable numbers of each groups (A - L) and 5\% confidence limits obtained using FDA's Bacterial Analytical Manual [26]. In sake-kasu (S), both prokaryote and eukaryote were not detected by the method $\left(<0.3 \times 10^{5} \mathrm{MPN} \mathrm{g}^{-1}\right)$. T; Total numbers of microorganisms.

\begin{tabular}{|c|c|c|c|c|c|c|c|c|c|c|c|c|}
\hline \multirow[b]{2}{*}{ Groups } & \multicolumn{5}{|c|}{ komekouji-miso } & \multicolumn{4}{|c|}{ dry yeast } & \multicolumn{3}{|c|}{ komekouji, } \\
\hline & $\begin{array}{l}\text { Three } \\
\text { dilutions }\end{array}$ & Score & $\begin{array}{c}\times 10^{5} \\
\text { MPN g } \\
\text { matter }\end{array}$ & $\frac{5 \% \text { limits }}{\text { Low/High }}$ & $\begin{array}{l}\text { Three } \\
\text { dilutions }\end{array}$ & Score & $\begin{array}{c}\times 10^{5} \\
\text { MPN g } \\
\text { matter }\end{array}$ & $\begin{array}{l}\text { 5\% limits } \\
\text { Low/High }\end{array}$ & $\begin{array}{c}\text { Three } \\
\text { dilutions }\end{array}$ & Score & $\begin{array}{c}\times 10^{5} \\
\text { MPN g } \\
\text { matter }\end{array}$ & $\frac{5 \% \text { limits }}{\text { Low/High }}$ \\
\hline A & $10^{-4} 10^{-5} 10^{-6}$ & $3-2-0$ & 4.65 & $0.9 / 21$ & nd & & $<0.3$ & - & nd & & $<0.3$ & - \\
\hline B & $10^{-5} 10^{-6} 10^{-7}$ & $3-1-0$ & 21.5 & $4.5 / 90$ & nd & & $<0.3$ & - & nd & & $<0.3$ & - \\
\hline C & $10^{-5} 10^{-6} 10^{-7}$ & $1-1-0$ & 3.7 & $0.65 / 10$ & nd & & $<0.3$ & - & nd & & $<0.3$ & - \\
\hline $\mathrm{D}$ & $10^{-4} 10^{-5} 10^{-6}$ & $0-1-0$ & 0.15 & $0.01 / 0.6$ & nd & & $<0.3$ & - & nd & & $<0.3$ & - \\
\hline$E+F+G$ & $10^{-3} 10^{-4} 10^{-5}$ & $3-0-0$ & 0.12 & $0.02 / 0.5$ & nd & & $<0.3$ & - & nd & & $<0.3$ & - \\
\hline $\mathrm{E}$ & $10^{-5} 10^{-6} 10^{-7}$ & $0-1-0$ & 1.5 & $0.08 / 5.5$ & nd & & $<0.3$ & - & nd & & $<0.3$ & - \\
\hline $\mathrm{H}$ & $10^{-5} 10^{-6} 10^{-7}$ & $1-1-0$ & 3.7 & $0.65 / 10$ & nd & & $<0.3$ & - & nd & & $<0.3$ & - \\
\hline I & nd & & $<0.3$ & - & $10^{-7} 10^{-8} 10^{-9}$ & $3-1-0$ & 8600 & $\begin{array}{c}1800 / \\
360000\end{array}$ & nd & & $<0.3-$ & - \\
\hline K & nd & & $<0.3$ & - & nd & & $<0.3$ & - & $10^{-5} 10^{-6} 10^{-7}$ & $0-1-0$ & 1.5 & $0.075 / 5.5$ \\
\hline $\mathrm{L}$ & nd & & $<0.3-$ & - & nd & & $<0.3$ & - & $10^{-5} 10^{-6} 10^{-7}$ & $3-2-0$ & 46.5 & $9 / 210$ \\
\hline $\mathrm{T}^{*}$ & $10^{-5} 10^{-6} 10^{-7}$ & $3-3-0$ & 120 & $21 / 500$ & $10^{-7} 10^{-8} 10^{-9}$ & $3-1-0$ & 8600 & $\begin{array}{c}1800 / \\
360000\end{array}$ & $10^{-5} 10^{-6} 10^{-7}$ & $3-3-0$ & 120 & $21 / 500$ \\
\hline
\end{tabular}

MERFLs), $\beta$-Proteobacteria (Group F, 2 MERFLs), $\gamma$-Proteobacteria (Group G, 2 MERFLs), and uncultured and unnamed bacterium (Group H, 5 MERFLs) (Table 1). MERFLs for 18S rDNA were divided into 5 groups as the followings; Hemiascomycetes (Group I, 8 MERFLs), Sordariomycetes (Group J, one MEPFL), Eurotiomycetes (Penicillium spp.; Group K, 3 MERFLs), and Eurotiomycetes (Aspergillus spp.; Group L, 8 MERFLs) (Table 1).

Most of MERFLs of isolates were placed in the same OUT as the MPN vials of the original samples as the following (Table 1); in Group A, two isolates (MiP4, MiP6) and the 7 vials (MuP10 $0^{-3} 1 \mathrm{H}, \mathrm{MuP} 10^{-3} 3 \mathrm{H}$, $\mathrm{MuP} 10^{-4} 1 \mathrm{H}, \mathrm{MuP}^{-4} 2 \mathrm{H}, \mathrm{MuP} 10^{-4} 3 \mathrm{H}, \mathrm{MuP}^{-5} 0^{-5} 1 \mathrm{H}, \mathrm{MuP}^{-5} 0^{-5} \mathrm{H}$ ) were placed in the same OUT (Table 1); in Group B, two isolates (MiP3,MiP5) and two vials $\left(\mathrm{MuP}^{-5} 0^{-5} \mathrm{H}, \mathrm{MuP} 10^{-5} 2 \mathrm{H}\right)$ were placed in the same OUT (Table 1); in Group I, two isolates (PiE1, PiE2) and four vials (PuE10 $0^{-8} 1 \mathrm{H}, \mathrm{PuE} 10^{-8} 2 \mathrm{H}, \mathrm{PuE} 10^{-8} 3 \mathrm{H}$, PuE $10^{-9} 2 \mathrm{H}$ ) were placed in the same OUT (Table 1); in Group K, one isolate (KiE2) and one vial (KuE10 $\left.{ }^{-6} 1 \mathrm{H}\right)$ were placed in the same OUT (Table 1); in Group L, two isolates (KiE3, KiE4) and five vials (KuE10 ${ }^{-5} 1 \mathrm{H}$, $\mathrm{KuE} 10^{-5} 2 \mathrm{H}, \mathrm{KuE} 10^{-5} 3 \mathrm{H}, \mathrm{KuE} 10^{-6} 2 \mathrm{H}, \mathrm{KuE} 10^{-6} 3 \mathrm{H}$ ) were placed in the same OUT (Table 1). These results indicated that microorganism included in food sample were properly affiliated using the MPN vials without isolation. As total MERFLs of most of the MPN vials in komekouji $(\mathrm{K})$ and dry yeast $(\mathrm{P})$ were the same as those of isolates and reference strains, the both samples were suggested to include almost pure single microorganism.

Bacillus spp. (Group A and B) were amplified preferentially to the other gram positive bacterial group (Group $\mathrm{C}$ and $\mathrm{D}$ ) and gram negative bacterial group (Group E, F and G) by 41f/1066r primers as the followings; all the Bacillus spp. (Group A and B) were the major MERFLs, indicated as " $\mathrm{H}$ ", in the MPN vials, while $20 \%$ of the other gram positive bacterial group (Group $C$ and $D$ ) was the major MERFLs, and no gram negative bacterial group (Group E, F and G) were the major MERFLs (Table 1), which were coincident with the former manuscripts [2] [3].

For 18S rDNA, difference between the theoretical MERFL and the measured MERFL, which caused to decrease precision of pyrogenetic estimation as described in the former papers [21] [22], was inevitably caused by used restriction enzyme as the followings; contiguous fragments of $354 \mathrm{bp}$ and $356 \mathrm{bp}$ in theoretical Alu I RF of Asperigillus spp. (Group L) were misread as one fragment in the respective measured Alu I RF; those of 353 bp and 356bp in theoretical Alu I RF of most Penicillium spp. (Group K) were misread as one fragment in the respective measured Alu I RF; those of 119 bp and $120 \mathrm{bp}$ in theoretical Rsa I RF and those of $151 \mathrm{bp}$ and $160 \mathrm{bp}$ 
of Hha I RFs of G.zaea (Group J) were misread as one fragment in the respective measured RFs; contiguous fragments of 177 bp and 174 bp and those of 155 bp and 151 bp in theoretical Hae III RFs of Saccharomyces spp. (Group K) were misread as one fragment in the respective measured RFs, the fragments of 99 bp in theoretical Rsa I RF of Saccharomyces spp. (Group K) were sometimes measured over 100 bp fragment due to the measuring error. As the relative mole ratios of these contiguous fragments were almost twice as those of the other fragments in the same RF, they were manually divided into 2 fragments in this study. Fragments from 100 bp to 103 bp of the measured Rsa I RF of Saccharomyces spp. (Group K) were manually eliminated in this study. Development of a program, which achieved these data processing automatically, may be useful to reduce a time for analysis.

Until now, following 5 restriction enzymes, HaeIII, HhI, Rsa I, ScrF1, and Alu I, have been used because they had more restriction sites in 16S rDNA than the others, in order to affiliate bacterial isolates precisely by using a fewer restriction enzymes [21] [22]. However such the restriction enzyme increased the opportunity of overlapped fragment, when they were used for longer DNA or sample having huge microbial diversity without isolation. Another combination of restriction enzymes, which had fewer restriction sites in 16S rDNA or 18S rDNA, was found suitable for such the analyses (unpublished results). Analysis using the other combination of restriction enzymes will be presented in the following manuscript.

\subsection{Enumeration of Each Prokaryotic and Eukaryotic Microbial Groups by MPN}

In komekouji (K), Group L, including Aspergillus spp., was enumerated to be $46.5 \times 10^{6} \mathrm{MPM} \mathrm{g}^{-1}$, and Group $\mathrm{K}$, including Penicillium spp., was enumerated to be $1.5 \times 10^{6} \mathrm{MPM} \mathrm{g}^{-1}$, and no other eukaryotic nor prokaryotic microorganisms were detected (Table 2, Figure 1). As the sample (K) included almost pure Aspergillus spp., the sample might be analyzed without cultivation as same as lactic acid bacterial groups in yoghurt [27]. In dry yeast (P), Group I, including Saccharomyces group, was enumerated to be $8600 \times 10^{6} \mathrm{MPM} \mathrm{g}^{-1}$, which was higher than that estimated by dilution plate count $\left(220 \times 10^{6} \mathrm{CFU} \mathrm{g}^{-1}\right.$; unpublished result), and no other eukaryotic nor prokaryotic microorganisms was detected (Table 2). As the sample (P) included almost pure Saccharomyces group, the sample might be analyzed without cultivation as same as lactic acid bacterial groups in yoghurt [27].

In komekouji-miso (M), eukaryotic microorganism was not detected. As prokaryotic microorganisms, Group $\mathrm{B}$ (the other Bacillus spp.) was numerically dominant, which was enumerated to be $21.5 \times 10^{6} \mathrm{MPM} \mathrm{g}^{-1}$, followed by Group A (B. subtilis group.; $4.65 \times 10^{6} \mathrm{MPM} \mathrm{g}^{-1}$ ), and Group C (the other Firmicutes; $3.7 \times 10^{6} \mathrm{MPM}$ $\mathrm{g}^{-1}$ ) (Table 2, Figure 1). Number of Group A was similar level as those reports, in which $B$. subtilis originated from soybean was present at $10^{4} \sim 10^{6} \mathrm{CFU} \mathrm{g}{ }^{-1}$ during miso fermentation, and decreased to under $10^{4} \sim 10^{5}$ CFU g ${ }^{-1}$ [28] [29]. Because of the difference of used incubation medium, total bacterial number in komekoujimiso (K) in this study was higher than that of the former study using MRS medium for lactic acid bacteria [27], and lactic acid bacteria was not detected in this study (Table 2). No Aspergillus spp. added with komekoji, nor

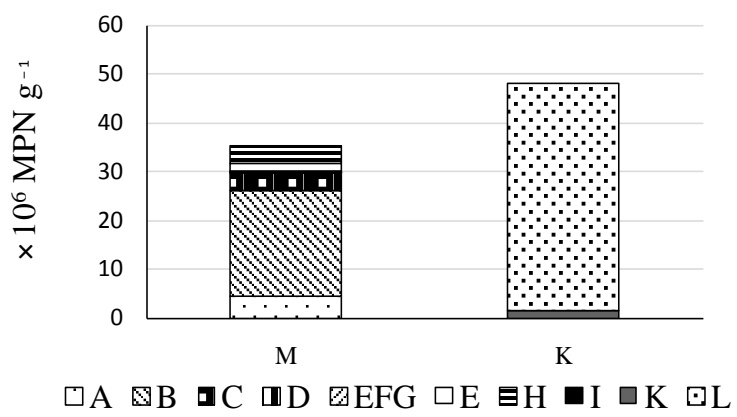

Figure 1. Numbers of microbial groups estimated by MPN and MERFLP in komekouji-miso (M), and komekouji (K). Number of the other Bacillus spp. (Group A; $\because$ ), B. subtilis (Group B; the other Firmicutes (Group C; 1 , Actino-

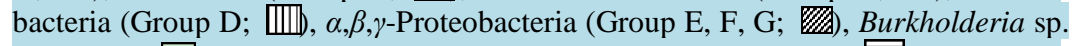
(Group E; $\square$ ), unidentified and uncultured bacteria (Group H; $\mathrm{Z}$, Saccharomyces sp. (Group I; $\square$ ), Penicillium spp. (Group K; $\square$ ), and Aspergillus spp. (Group L; 鹿) were presented. 
yeast, which progressed alcohol fermentation, were also detected in komekouji-miso $\left(<0.3 \times 10^{5} \mathrm{MPN} \mathrm{g}^{-1}\right)$ (Table 2). The sample M also included lower number of Group D (Actinobacteria; $0.15 \times 10^{6} \mathrm{MPM} \mathrm{g}^{-1}$ ), Group $\mathrm{E}$ (Burkhokderia sp.; $1.5 \times 10^{6} \mathrm{MPM} \mathrm{g}^{-1}$ ), and Group E, F, G (the other $\alpha, \beta, \gamma$ proteobacteria; $0.12 \times 10^{6} \mathrm{MPM}$ $\mathrm{g}^{-1}$ ) (Table 2, Figure 1). In sake-kasu (S), both prokaryote and eukaryote were not detected by the method, while bacteria affiliated to be Goup A (SiP5), Group B (SiP1), Group C (SiP2, SiP4), and Group G (SiP3) were isolated from the lowest dilution agar plate. As skekasu was residue filtered rice wine from moromi after finish of alcohol fermentation and sterilization by heating at 60 to $65^{\circ} \mathrm{C}$, eukaryotic microorganisms, such as Aspergillus spp. and Saccharomyces spp., which progressed alcohol fermentation, nor prokaryotic bacteria were not founded in MPN vials, but spore forming bacteria such as Bacillus subtilis (group A; SiP5), B. pumilus (group B; SiP1), Clostridium barati (group C; SiP2), and C. botulinum (group C; SiP4) were isolated in lowest dilution agar plate as heat tolerant bacteria (Table 1).

As PCR amplification were not tested under $10^{-5}$ dilution vials and lower detection limit was high $\left(<0.3 \times 10^{5}\right.$ MPN g ${ }^{-1}$ ) in the present experiment except for prokaryotic microorganisms in komekouji-miso (K) (Table 1, Table 2), the lower detection limit could be lowered by using more effective DNA purification method.

\section{Conclusions}

By DGGE [8]-[11], which used directly extracted DNA, exact ratio of each microbial groups was not obtained due to PCR bias and it was no use to compare the numbers and composition of prokaryotic microorganisms to those of eukaryotic microorganisms because of a difference in the PCR amplification rates [15]-[18]. As numbers of each microbial groups were estimated by MPN not by an amount of the amplified DNA in this method as described in the former manuscripts [1] [2], the difference in the primers did not affect the numbers and composition of numerically dominant microorganisms but their effect was limited in numerically minor microorganisms. Present results indicated that using both universal primers for eukaryotic and prokaryotic microorganisms, each group of prokaryotic and eukaryotic microorganisms were simultaneously enumerated without any preliminary information nor setting up standard curve, which were required for real time PCR. The method seemed useful not only to evaluate whole microbial compositional change during traditional fermentation process, and manure composting process, but also the variety of other purpose such as to ensure food safety by evaluating unintended or unexpected contamination or proliferation of opportunistic pathogens or foodborne pathogens or non-pathogenic spoilage microorganisms during food distribution system.

In this study, universal PCR primers for eukaryotic and prokaryotic microorganisms were used to evaluate what kinds of microorganisms was mainly included in the sample. Another combination of universal primers and selective primers will afforded more detailed information of each microbial group, and functional or toxicological information of each microbial group will similarly be obtained by changing DNA primers.

\section{Acknowledgements}

We thank Mr. N. Osako, and Mr. R. Kizuka, the former undergraduate students of Fukuoka Institute of Technology, for analysis of samples.

\section{References}

[1] Watanabe, K. and Okuda, M. (2003) Method and System for Searching for Relationships between Base Sequences in Genes. Japanese Patent 3431135; (2006) US Patent 7,006,924.

[2] Watanabe, K., Horinishi, N. and Matumoto, K. (2015a) Antibiotic-Resistant Bacterial Group in Field Soil Evaluated by a Newly Developed Method Based on Restriction Fragment Length Polymorphism Analysis. Advances in Microbiology, 5, 807-816. http://dx.doi.org/10.4236/aim.2015.512085

[3] Watanabe, K., Horinishi, N., Matumoto, K., Tanaka, A. and Yakushido, K. (2015) Bacterial Groups Concerned with Maturing Process in Manure Production Analyzed by a Method Based on Restriction Fragment Length Polymorphism Analysis. Advances in Microbiology, 5, 832-841. http://dx.doi.org/10.4236/aim.2015.513088

[4] Smith, C.J. and Osborn, A.M. (2009) Advantages and Limitations of Quantitative PCR(Q-PCR)-Based Approaches in Microbial Ecology. FEMS Microbiology Ecology, 67, 6-20. http://dx.doi.org/10.1111/j.1574-6941.2008.00629.X

[5] Park, E., Chang, H., Kim, K., Nam, Y., Roh, S.W. and Bae, J. (2009) Application of Quantitative Real-Time PCR for Enumeration of Total Bacterial, Archaeal, and Yeast Populations in Kimchi. The Journal of Microbiology, 47, 682-685. http://dx.doi.org/10.1007/s12275-009-0297-1 
[6] Lakaniemi, A.M., Hulatt, C.J., Wakeman, K.D., Thomas, D.N. and Puhakka, J.A. (2012) Eukaryotic and Prokaryotic Microbial Communities during Microalgal Biomass Production. Bioresource Technology, 124, 387-393.

http://dx.doi.org/10.1016/j.biortech.2012.08.048

[7] Teranishi, H. and Ouchi, K. (2014) Detection of Bacteria, Fungi, and Viruses by a Real-Time PCR Assay Using Universal Primers and Probes from Blood in Patients with Febrile Neutropenia. Kawasaki Medical Journal, 40, 1-11.

[8] Mills, D.A., Johannsen, E.A. and Cocolin, L. (2002) Yeast Diversity and Persistence in Botrytis-Affected Wine Fermentations. Applied and Environmental Microbiology, 68, 4884-4893. http://dx.doi.org/10.1128/AEM.68.10.4884-4893.2002

[9] Hierro, N., Esteve-Zarzoso, B., González, Á., Mas, A. and Guillamón, J.M. (2006) Real-Time Quantitative PCR (QPCR) and Reverse Transcription-QPCR for Detection and Enumeration of Total Yeasts in Wine. Applied and Environmental Microbiology, 72, 7148-7155. http://dx.doi.org/10.1128/AEM.00388-06

[10] Guo, R., Chen, Z., Chen, N. and Chen, M.D. (2010) Quantitative Real-Time PCR Analysis of Intestinal Regular Fungal Species in Fecal Samples From Patients With Chronic Hepatitis B Virus Infection. Science, 41, 591-596. http://dx.doi.org/10.1309/lmmc0wvzxd13pujg

[11] Lottmann, J., O’Callaghan, M., Baird, D. and Walter, C. (2010) Bacterial and Fungal Communities in the Rhizosphere of Field-Grown Genetically Modified Pine Trees (Pinus radiata D.). Environmental Biosafety Research, 9, 25-40. http://dx.doi.org/10.1051/ebr/2010007

[12] Duartea, S., Pascoala, C., Alvesb, A., Correiab, A. and Cássioa, F. (2010) Assessing the Dynamic of Microbial Communities during Leaf Decomposition in a Low-Order Stream by Microscopic and Molecular Techniques. Microbiological Research, 165, 351-362. http://dx.doi.org/10.1016/j.micres.2009.06.002

[13] Suzuki, C., Takenaka, M., Oka, N., Nagaoka, K. and Karasawa, T. (2012) A DGGE Analysis Shows That Crop Rotation Systems Influence the Bacterial and Fungal Communities in Soils. Soil Science and Plant Nutrition, 58, 288-296. http://dx.doi.org/10.1080/00380768.2012.694119

[14] Xu, Y., Xie, Y.B., Zhang, X.R., Chen, C., Xiang, H. and Xie, Q. (2013) Monitoring of the Bacterial and Fungal Biodiversity and Dynamics during Massa Medicata Fermentata Fermentation. Applied and Environmental Microbiology, 97, 9647-9655.

[15] Suzuki, M.T. and Giovannoni, S.J. (1996) Bias Caused by Template Annealing in the Amplification of Mixtures of 16S rRNA Genes by PCR. Applied and Environmental Microbiology, 62, 625-630.

[16] Ishii, K. and Fukui, M. (2001) Optimization of Annealing Temperature to Reduce Bias Caused by a Primer Mismatch in Multitemplate PCR. Applied and Environmental Microbiology, 67, 3753-3755. http://dx.doi.org/10.1128/AEM.67.8.3753-3755.2001

[17] Neilson, J.W., Jordan, F.L. and Maier, R.M. (2013) Analysis of Artifacts Suggests DGGE Should Not Be Used for Quantitative Diversity Analysis. Journal of Microbiological Methods, 92, 256-263. http://dx.doi.org/10.1016/j.mimet.2012.12.021

[18] Direito, S.O.L., Zaura, E., Little, M., Ehrenfreund, P. and Röling, W.F.M. (2014) Systematic Evaluation of Bias in Microbial Community Profiles Induced by Whole Genome Amplification. Environmental Microbiology, 16, 643-657. http://dx.doi.org/10.1111/1462-2920.12365

[19] Smit, E., Leeflang, P., Glandorf, B., Elsas, J.D.V. and Wernars, K. (1999) Analysis of Fungal Diversity in the Wheat Rhizosphere by Sequencing of Cloned PCR-Amplified Genes Encoding 18S rRNA and Temperature Gradient Gel Electrophoresis. Applied and Environmental Microbiology, 65, 2614-2621.

[20] Gao, Z., Li, B., Zheng, C. and Wang, G. (2008) Molecular Detection of Fungal Communities in the Hawaiian Marine Sponges Suberites zeteki and Mycale armata. Applied and Environmental Microbiology, 74, 6091-6101. http://dx.doi.org/10.1128/AEM.01315-08

[21] Watanabe, K., Okuda, M. and Koga, N. (2008) A Newly Developed System Based on Multiple Enzyme Restriction Fragment Length Polymorphism-An Application to Proteolytic Bacterial Flora Analysis. Soil Science and Plant Nutrition, 54, 204-215. http://dx.doi.org/10.1111/j.1747-0765.2007.00230.x

[22] Watanabe, K. and Koga, N. (2009) Use of a Microchip Electrophoresis System for Estimation of Bacterial Phylogeny and Analysis of $\mathrm{NO}_{3}{ }^{-}$Reducing Bacterial Flora in Field Soils. Bioscience Biotechnology and Biochemistry, 73, 479-488. http://dx.doi.org/10.1271/bbb.70712

[23] Weidner, S., Arnold, W. and Puhler, A. (1996) Diversity of Uncultured Microorganisms Associated with the Seagrass Halophilastipulacea Estimated by Restriction Fragment Length Polymorphism Analysis of PCR-Amplified 16S rRNA Genes. Applied and Environmental Microbiology, 62, 766-771.

[24] Cole, J.R., Chai, B., Farris, R., Wang, Q., Kulam-Syed-Mohideen, A.S., McGarrell, D.M., Bandela, A.M., Cardenas, E., Garrity, G.M. and Tiedje, J.M. (2007) The Ribosomal Database Project (RDP-II): Introducing myRDP Space and Quality Controlled Public Data. Nucleic Acids Research, 35, D169-D172. http://dx.doi.org/10.1093/nar/gkl889 
[25] Nei, M. and Li, W.H. (1979) Mathematical Model for Studying Genetic Variation in Terms of Restriction Endonucleases. Proceedings of the National Academy of Sciences of the United States of America, 76, 5269-5273. http://dx.doi.org/10.1073/pnas.76.10.5269

[26] Blodgett, R. (2010) FDA, Bacterial Analytical Manual, Appendix 2 Most Probable Number from Serial Dilutions. http://www.fda.gov/Food/FoodScienceResearch/LaboratoryMethods/ucm109656.htm

[27] Matsumoto, K., Shimada, K., Horinishi, N. and Watanabe, K. (2016) Evaluation of the Method Based on Restriction Fragment Length Polymorphism Analysis as Simple Analysis Method of Lactic Acid Bacteria in Foods. Food and Nutrition Sciences, 7, 163-172. http://dx.doi.org/10.4236/fns.2016.73018

[28] Onda, T., Yanagida, F., Tsuji, M., Shinohara, T. and Yokotsuka, K. (2003) Time Series Analysis of Aerobic Bacterial Flora during Miso Fermentation. Letters in Applied Microbiology, 37, 162-168. http://dx.doi.org/10.1046/j.1472-765X.2003.01371.x

[29] Onda, T., Yanagida, F., Uchimura, T., Tsuji, M., Shinohara, T., Ogino, S. and Yokotsuka, K. (2003) Analysis of Lactic Acid Bacterial Flora during Miso Fermentation. Food Science and Technology Research, 9, 17-24. http://dx.doi.org/10.3136/fstr.9.17 